\title{
A ESTIGMATIZAÇÃO DAS DOENÇAS MENTAIS NA SOCIEDADE BRASILEIRA
}

\section{Milena Stoever Bittencourt ${ }^{1}$; Luiza Moscato Soares²; Janaina Pereira Pretto Carlesso $^{3}$}

\section{RESUMO}

A estigmatização das doenças mentais é uma problemática muito comum na sociedade brasileira. Essa questão, aliada ao fato de que o Brasil é o país que apresenta o maior número de casos de depressão da América Latina, é acentuada e desperta a atenção e preocupação da comunidade científica, bem como de psicólogos e demais profissionais de saúde. Sob tal ótica, o presente artigo temcomo objetivo dissertar a respeito do estigma relacionado às doenças mentais na sociedade brasileira. Para tanto, utilizou-se do método de revisão narrativa da literatura. Os dados analisados sugerem que o estigma é um fato histórico e cíclico, reforçado pelas classes sociais. Como consequência, constatam-se prejuízos a uma comunidade já enfraquecida, além do desmembramento da sociedade e do agravamento de preconceitos voltados ao doente mental.

Palavras-chave: Preconceito; Discriminação; Social; Saúde Mental; Transtornos Mentais.

Eixo Temático: Direitos, Políticas Públicas e Diversidade (DPD).

\section{INTRODUÇÃO}

A prática psiquiátrica atual tem como um dos principais objetivos a reintegração social do paciente. Contudo, o estigma criado sobre a doença mental representa um enorme obstáculo para a concretização desse propósito. As crenças negativas construídas pelo imaginário social acerca dos sujeitos com diagnósticos psiquiátricos, além de comprometer o tratamento ao serem internalizadas enquanto verdades identitárias pelo paciente, ainda os prejudica ao emergirem através de microviolências cotidianas que dificultam o acesso aos cuidados de saúde e às possibilidades de integração social (LEÃO, NASCIMENTO, 2019).

Considerando que cerca de 700 milhões de pessoas no mundo sofrem de transtornos mentais (OMS, 2017), é questionável como o debate a respeito do

\footnotetext{
${ }_{1}^{1}$ Autor/Apresentador - Universidade Franciscana (UFN), milenastoever@gmail.com

2 Demais Autores - Universidade Franciscana (UFN), luiza.vegeta8000@gmail.com

${ }^{3}$ Orientador - Universidade Franciscana (UFN), janaina.carlesso@ufn.edu.br
} 
estigma voltado ao paciente psiquiátrico é escasso, perpetuando os malefícios da exclusão social desses sujeitos. A doença mental é vista como desviante, fora do padrão de características entendidas como "normais" dos espaços sociais, uma espécie de herdeira da loucura e, assim como ela, marginalizada (FILHO et.al, 2013). O estigma gera um ciclo vicioso de exclusão social, gerando uma forte barreira para o desenvolvimento positivo de indivíduos com doenças mentais, muitas vezes impedindo a reintegração social mais do que a própria doença.

Sendo assim, o presente artigo refere-se ao estigma presente na sociedade brasileira no que tange aos distúrbios psiquiátricos. A partir deste, compreende-se que o estigma pode acentuar sintomas psiquiátricos, diminuir a autoestima e reduzir a eficácia e a continuidade de tratamento psicológico (APA, 2020). Além disso, no Brasil, afirma-se que os portadores de doenças psiquiátricas são também "[...] grupo dos mais vulneráveis aos crimes violentos". Por exemplo, pacientes com doenças mentais graves têm 12 vezes mais chances de sofrer um crime violento que a população geral" (HARA, PAPROCKI, ROCHA, 2015, p. 594).

A investigação desta conjuntura foi realizada - a partir de uma revisão bibliográfica narrativa - no interesse de compreender os impactos da estigmatização do paciente psiquiátrico, propondo mudanças efetivas para a luta contra esta problemática. Tal discussão é essencial, visto o desejo perpetuado pelo sensocomum de afastar pessoas com diagnósticos psiquiátricos, segregando-as, a partir da crença que os distúrbios mentais são perigosos, ou mesmo tornam os sujeitos portadores "defeituosos". Desta forma, considerando a relevância e contemporaneidade da temática, o objetivo do presente estudo é dissertar a respeitodo estigma relacionado às doenças mentais na sociedade brasileira.

\section{METODOLOGIA}

O presente estudo adotou como método a revisão bibliográfica narrativa, na qual a escolha do conteúdo utilizado ocorre a partir de um caráter amplo, visando maior proveito e síntese qualitativa na escolha da bibliografia utilizada (BERNARDO, NOBRE, \& JATENE, 2004). De acordo com Lakatos e Marconi (1996), um estudo 
bibliográfico traz flexibilidade ao pesquisador, admitindo uma carga teórica variada. Para tanto, este trabalho utilizou-se de livros e artigos científicos nacionais e internacionais em material digital. Para buscas de ferramentas externas, os descritores utilizados foram: estigma, preconceito, discriminação, social e saúde mental. Ademais, confere-se que as bases de dados consultadas foram Scielo, Google Acadêmico e Portal da Capes.

\section{RESULTADOS E DISCUSSÕES}

\subsection{A ESTIGMATIZAÇÃO}

A reforma psiquiátrica trouxe transformações significativas à perspectiva sobre o adoecimento mental, a medida em que os serviços substitutivos foram uma resposta às atrocidades cometidas dentro das grandes instituições de internações, nas quais aqueles vistos como loucos eram também entendidos como menos humanos. No entanto, apesar das inovações e do desenvolvimento na área médicae psiquiátrica, as marcas deixadas pela história são salientes, uma vez que acomunidade brasileira é constituída por normas sociais repercutidas ao longo das gerações. Tais normas são expectativas quanto o que os outros vão pensar sobre determinado traço ou comportamento, podendo ser aprovado ou desaprovado. Apesar de serem apenas juízos coletivos, as normas motivam diversas redes de decisão, pois são frequentemente internalizadas como verdades. Nesse sentido, as normas sociais costumam ser rígidas, cristalizadas dentro de valores morais e são envoltas por uma resistência absurda a se desfazerem, pois são mergulhadas por estigmas (BICCHIERI, 2017).

No discurso sociológico, o conceito de estigma costuma assumir o significado que Erving Goffman (1922-1988) Ihe atribuiu em sua obra "Stigma - Notes on the Management of Spoiled Identity", de 1963. Do grego, a palavra "estigma" significa picada, feita com ferro em brasa no braço dos escravos, marginais e criminosos. Não era relacionada aos transtornos mentais, mas à vergonha, humilhação e desvalorização.

O conceito atual é muito mais amplo. Para fins de praticidade, a visão de estigma da qual utiliza-se este artigo é, portanto, a de Goffman, conceituando como 
"situação do indivíduo que é inabilitado para a aceitação social plena" e refere-se a "um atributo profundamente depreciativo" (Goffman, 1982, p. 4).

No caso da área da saúde mental, a loucura é o fenômeno que, no mundo moderno, ocupa o mesmo nível de estigma alcançado pela lepra no mundo medieval. Contudo, diferente da lepra - que o isolamento era devido a um caráter exclusivo da dimensão médica -, o louco é aprisionado por "significações políticas, sociais, religiosas, econômicas e morais" (FOUCAULT, 1972, p. 61). Esses indivíduos vistos como indesejados eram errantes, tomados por loucos ao possuírem juízos e comportamentos que de alguma forma iam contra a "razão" dominante, sendo excluídos da sociedade. Com o avanço das tecnologias políticas de caráter anátomoclínico, a disciplina antes ilustrada pelas figuras que governam, agora ultrapassa a dimensão do corpo. Então, criam-se as doenças institucionalizadas, normalizadoras, de forma que a doença mental passa a ser a "máscara" da loucura (FOUCAULT, 1972). Nessa conformidade, os distúrbios mentais, hoje, carregam o peso do estigma antes visto na loucura e agora dissolvido nos diagnósticos psiquiátricos.

Nesse sentido, tem-se que o estigma frequentemente emerge a partir da desinformação ou do medo. Representações enganosas da mídia a respeito de distúrbios psicológicos, por exemplo, contribuem para ambos os fatores, frequentemente percebendo a doença mental de forma negativa e violenta. Um estudo publicado em abril de 2020 trabalha com o exemplo do filme "Coringa", de 2019. Tal obra retrata o personagem principal como uma pessoa perturbada eextremamente violenta. O estudo afirma que o filme "was associated with higher levels of prejudice towards mental illness" (em tradução livre, "foi associado comaltos níveis de preconceito contra doenças mentais"). O mesmo artigo tambémdebate sobre como a representação do Coringa pode exacerbar o estigma pessoal einterior sobre aqueles que sofrem com distúrbios psicológicos, retardando a procura de ajuda profissional (SCARF; ZIMMERMAN; WINTER; et al, 2020).

Assim, é importante perceber tal fenômeno como uma fonte de estresse e desvantagem social. O estigma acaba por rotular e excluir o indivíduo, em um contexto em que o desequilíbrio de poder é exercido e acentuado. 
Em perspectiva antropológica, cada um organiza o mundo a partir da relação individualidade-alteridade, da consciência do ser único, de ter uma identidade específica que distingue um do outro. Acrescendo-se a isso o fato de o ser humano ser precário (mortal, cosmicamente insignificante e biologicamente frágil), tem 0 caldo de cultura psicológico para o desenvolvimento do preconceito e estigma. Reforça a identidade frágil a partir da desvalorização e exclusão do outro. A exclusão dos enfermos condiz com a fantasia de que os outros são sadios. A estigmatização da doença mental traz a ilusão da saúde mental (ROCHA; HARA \& PAPROCKI, 2015).

\subsection{AS REPERCUSSÕES DA ESTIGMATIZAÇÃO DO INDIVÍDUO COM TRANSTORNOS MENTAIS}

O portador de doença mental é, na sociedade brasileira, uma espécie de pária social: não se fala sobre ele ou sobre o que se tem. Simplesmente é isolado do convívio, o que gera diversas consequências sociais, psicológicas e econômicas: essa é a marca social, a cicatriz, o estigma. Percebe-se nisso que a discriminação popular piora a situação de uma comunidade já fragilizada, além de comprovar a necessidade do combate ao preconceito referente às doenças psíquicas em prol de um bem-estar social nacional.

Sendo um dos principais obstáculos à procura de cuidados pelas pessoascom perturbação mental, o preconceito se torna um dos grandes atenuantes das dificuldades cotidianas daqueles acometidos pelos distúrbios psiquiátricos (GUARNIERO, BELLINGHINI \& GATTAZ, 2012). Em razão da internalização do estigma pelo paciente, ele acredita que os estereótipos negativos associados à sua doença são verdadeiros e fazem parte da constituição da sua identidade. Dessa forma, concorda com a ideia de defectividade a qual corrói sua autoestima (LEÃO, NASCIMENTO, 2019). Assim, a pergunta que fica é: como aquele que sofre com algum tipo de transtorno mental pode pertencer à sociedade de forma produtiva e participativa, sem estigma, nem o peso de estorvo ou inviabilidade?

Em "Holocausto Brasileiro", livro de Daniela Arbex, é apresentado um período conturbado marcado pelos maus tratos ocorridos no Hospital Colônia de Barbacena, em Minas Gerais. Ali, pessoas com doenças e transtornos mentais eram tratadas de forma desumana na década de 1960, abandonadas por seus familiares e condenadas a viver entre seus próprios dejetos e sob risco permanente de uma 
série de doenças. De acordo com Ed Otsuka, membro do Conselho Regional de Psicologia de São Paulo, “(...) elas não eram consideradas sujeitos, mas sim, objetos de intervenção pelos 'detentores do poder médico'. Os seus direitos fundamentais, como liberdade e dignidade, foram retirados" (VIANA, 2017).

A partir disso, fica claro que, a fim de combater o estigma associado às doenças mentais na sociedade brasileira, é necessário, primeiramente, garantir e reforçar os direitos humanos, principalmente em comunidades e indivíduos fragilizados e dependentes. Isso é, se faz vital que os direitos humanos em áreas médicas - como nos hospitais psiquiátricos - sejam fortificados e estimulados. Esse éo primeiro passo para combater o preconceito e a discriminação dos distúrbios psicológicos.

A militância neste setor já rendeu alguns progressos. Hoje, comemora-se no dia 18 de maio a Luta Antimanicomial. Além disso, o orçamento nacional destinado à saúde mental cresceu 200\% entre 2002 e 2011. Contudo, principalmente fora do meio médico, as doenças psiquiátricas continuam sendo encaradas como sinal de fraqueza, preguiça, frescura e incompetência. Nesse sentido, Nascimento e Leão (2019, p. 104) afirmam que:

As pessoas com transtorno mental severo e recorrente, ou com transtornos decorrentes do uso de álcool e outras drogas, historicamente carregam consigo estigmas que acarretam diversos tipos de dificuldades na adesão ao tratamento especializado e mesmo na participação social nos diversos âmbitos da vida. (NASCIMENTO, LEÂO, 2019, p.104).

Até mesmo em obras científicas percebe-se a desconsideração do indivíduo ao analisar os distúrbios mentais, ignorando uma visão humanizada das doenças e focando apenas no conflito, a partir de uma análise fria que desconsidera as esferas biopsicossociais de quem sofre de tais transtornos. Exemplo disso se dá por Foucault, em "História da Loucura", na qual o sociólogo deixa evidente que essaobra se propõe a estudar os mecanismos que levaram à ruptura entre "razão e desrazão", ou seja à estrutura da razão científica que preparou a oposição entre sentido e insensatez:

A bela retidão que conduz o pensamento racional à análise da loucura como doença mental deve ser reinterpretada numa dimensãovertical; e neste caso verifica-se que sob cada uma de suas formas ela oculta de uma maneira mais completa e também mais perigosa essa experiência trágica que tal retidão não conseguiu reduzir (FOUCAULT, 1972, p.48; 2003, p. 29) 
Como resultado desse preconceito, já temos citado que o estigma pode trazer mais desvantagens que a própria condição primária da doença mental para o indivíduo. Além da desumanização geral, os efeitos do fenômeno discriminatório são vastos. Revela-se que o indivíduo sofredor da estigmatização sofre, no contexto clínico, um aumento no estresse e no sofrimento psicológico, além de maior tendência no consumo de substâncias psicoativas, elevação de pressão arterial, ansiedade, entre outros (LEÃO \& SUSSI, 2021). Já no contexto social, as repercussões são incontáveis, variando desde uma redução nas oportunidades de emprego, até a maior vulnerabilidade a abusos físicos e sexuais.

\section{CONCLUSÃO}

O presente estudo bibliográfico permitiu um diálogo entre o estigma das doenças mentais, suas causas e suas implicações no contexto psiquiátrico e social. A partir do mesmo, foi possível verificar que a sociedade brasileira contemporânea possui enraizada as significações estereotipadas que preenchem os espaços socioculturais e perpetuam a visão do indivíduo com doenças mentais como culpado por sua condição, um pária social reduzido pela sua enfermidade.

As graves consequências desse estigma comprovam a necessidade de aumentar as forças contra o preconceito, bem como os esforços em implementar medidas de atenção psicossocial específica e de combate ao preconceito. Da mesma forma, é necessário trabalhar com uma maior sensibilização da comunidade brasileira, incluindo familiares e profissionais da saúde.

Pode-se afirmar que há polissemia nos processos de estigmatização sofridos por portadores de transtornos mentais. Em países que já trabalham com um modelo de atenção psicossocial há mais tempo, o engajamento concreto das pessoas na luta contra a estigmatização dos distúrbios psicológicos parece estar surtindo grandes resultados. As ações desenvolvidas na micropolítica do cotidiano se apresentam como os maiores recursos na inclusão social dos portadores de transtornos mentais.

Afirma-se além, que conter a discriminação acerca das doenças mentais não seria possível sem incluir também a disseminação de informações. Confere-se à mídia, principalmente a imprensa, a função de propagar os programas do SUS, bem como as realidades daqueles que sofrem com transtornos psiquiátricos, provocando 
a reflexão e a mudança de valores, e gerando novas atitudes nas gerações presentes e futuras. Ademais, afirma-se que a sistematização de relatos de estigmatização sob a forma de microviolências pode servir como referência para o acompanhamento de ações com foco na mitigação do estigma. Um esforço nessa direção poderia culminar em formas de enfrentamento para promover uma melhora da qualidade de vida das pessoas que sofrem com este estigma.

Tendo em vista o exposto, conclui-se que a estigmatização das doenças mentais na sociedade brasileira é altamente prejudicial para a integração social, e o desenvolvimento psicológico do indivíduo, além de retardar a busca do sujeito por ajuda psicológica profissional. Ressalta-se também que essa discriminação não é recente, porém a tendência foi intensificada pelas representações enganosas das grandes mídias. Recomenda-se, portanto, a conscientização das doenças mentais, bem como a produção de novos estudos que abordam o tema em questão, a fim de garantir uma melhor resposta do paciente psiquiátrico e prevenir o agravamento de suas condições, reintegrando-o à sociedade com êxito. 


\section{Referências}

BERNARDO, Wanderley Marques; Moacyr Roberto Cuce, NOBRE; JATENE, Fábio Biscegli. A prática clínica baseada em evidências: parte II - buscando as evidências em fontes de informação. Revista da Associação Médica Brasileira, 2004. Disponível em: < https://doi.org/10.1590/S0104-42302004000100045 >. Acesso em: 20/08/2021.

BICCHIERI. Norms in the wild: how to diagnose, measure, and change social norms. New York: Oxford University Press, 2017.

BORENSTEIN, Jeffrey M.D. Stigma, Prejudice and Discrimination Against People with Mental Illness. American Psychiatric Association (APA), 2020. Disponível em: < https://www.psychiatry.org/patients-families/stigma-and-discrimination >. Acesso em: 20/08/2021.

Estigma (sociologia) in Infopédia [em linha]. Porto: Porto Editora, 2003-2021. [consult. 2021-05-31 21:09:29]. Disponível em: < https://www.infopedia.pt/\$estigma(sociologia) >. Acesso em: 31/05/2021.

FILHO et. al. O estigma da doença mental e as Residências Terapêuticas no município de Volta Redonda - RJ. Texto Contexto Enferm, Florianópolis, 2013 AbrJun; 22(2): 327-34. Disponível em: < https://www.scielo.br/j/tce/a/LHTj68fy9yvKcDDPyHzDkpd/abstract/?lang=pt >. Acesso em: 31/08/2021.

FOUCAULT, Michel, Historie de la folie à l'âge classique. Paris: Gallimard, 1972. . História da Loucura na Idade Clássica. Tradução de José Teixeira Coelho Netto. - 7. ed. - São Paulo: Editora Perspectiva, 2003.

GOFFMAN, E. Estigma: notas sobre a manipulação da identidade deteriorada. LTC, 1981.

GUARNIERO, Francisco, B; BELLINGHINI, Ruth, H; GATTAZ, Wagner F. O. Estigma da esquizofrenia na mídia: um levantamento de notícias publicadas em veículos brasileiros de grande circulação. Arch. Clin. Psychiatry (São Paulo) 39 (3), 2012. Disponível em: < https://www.scielo.br/j/rpc/a/HQJyjhdS6cD3CtsFLhGKPfL/abstract/?lang=pt >. Acesso em 27/08/2021.

HARA, Cláudia; PAPROCKI, Jorge; ROCHA, Fábio Lopes. Doença Mental e Estigma. Revista Média de Minas Gerais, 2015. Disponível em: < http://www.rmmg.org/artigo/detalhes/1876 >. Acesso em: 31/08/2021.

LAKATOS, E. M.; MARCONI, M. de A. Fundamentos de metodologia científica. São Paulo: 1996.

LAKATOS, E. M.; MARCONI, M. DE A. Metodologia do trabalho científico. São Paulo: Atlas, 1996. 
NASCIMENTO, Larissa Alves do; LEÃO, Adriana. Estigma social e estigma internalizado: a voz das pessoas com transtorno mental e os enfrentamentos necessários. História, Ciências, Saúde - Manguinhos, Rio de Janeiro, v.26, n.1, jan.mar. 2019, p.103-121.

NUNES, Mônica; TORRENTÉ, Maurice. Estigma e violência no trato com a loucura: narrativas de centros de atenção psicossocial, Bahia e Sergipe. Revista de Saúde Pública, v.43, supl.1, p.101-108. 2009.

OFFMAN, E. Estigma: notas sobre a manipulação da identidade deteriorada. LTC, 1981.

Organização Mundial da Saúde. Plano de Ação sobre a Saúde Mental: Revisão Intermediária. CSP29/INF/7, 2017. Disponível em: < https://iris.paho.org/bitstream/handle/10665.2/34430/CSP29-INF-7-Hp.pdf? sequence=36\&isAllowed=y $>$. Acesso em: 31/05/2021.

ROCHA, José Manuel de Sacadura. Doença mental e controle social: Uma releitura a partir de Michel Foucault. Genjuridico, 2017. Disponível em:

<http://genjuridico.com.br/2017/07/05/doenca-mental-e-controle-social-uma-releiturapartir-de-michel-foucault/>. Acesso em 31/05/21.

ROCHA, Fábio Lopes; HARA, Cláusia; PAPROCKI, Jorge. Doença Mental e Estigma. Revista Média de Minas Gerais (RMMG), 2015, p. 590 - 596. Disponível em: http://www.rmmg.org/artigo/detalhes/1876. Acesso em 19/08/21.

SCARF, Damian; ZIMMERMAN, Hannah; WINTER; Taylor; et al. Association of Viewing the Films Joker or Terminator: Dark Fate With Prejudice Toward Individuals With Mental Illness. JAMA Netw Open. 2020. Disponível em: < https://jamanetwork.com/journals/jamanetworkopen/fullarticle/2764842 >. Acesso em 20/08/2.

VIANA, Luana. Falta de informação ajuda a estigmatizar transtornos mentais. Portal Drauzio Varella, 2017. Disponível em: <

https://drauziovarella.uol.com.br/reportagens/falta-de-informacao-ajuda-a-estigmatizartranstornos-mentais/ >. Acesso em: 20/08 